\title{
Quantification of River Bank Erosion and Bar Deposition in Chowhali Upazila, Sirajganj District of Bangladesh: A Remote Sensing Study
}

\author{
Md. Shareful Hassan1, Syed Mahmud-ul-islam² \\ ${ }^{1}$ Center for Environmental Change Studies and Management, Dhaka, Bangladesh \\ ${ }^{2}$ Department of Sustainable Development, Environmental Science and Engineering, \\ KTH-Royal Institute of Technology, Stockholm, Sweden \\ Email: shareful@gmx.com
}

Received 19 November 2015; accepted 9 January 2016; published 12 January 2015

Copyright (C) 2016 by authors and Scientific Research Publishing Inc.

This work is licensed under the Creative Commons Attribution International License (CC BY). http://creativecommons.org/licenses/by/4.0/

(c) (i) Open Access

\section{Abstract}

River bank erosion is one of the frequent but the most unpredictable disasters that occur every year in Bangladesh. In this paper, Landsat TM-5 and Landsat-8 imageries from 1989 and 2015 were used to detect changes of present land use, river erosion and bar deposition in Chowhali Upazila, Sirajganj district of Bangladesh. This study reveals that human settlement, forest, seasonal crops and agriculture features decrease, while river coverage increases dramatically. About 1340 hectare areas have been eroded, while 630 hectares are deposited as channel bar in the study area over the last 26 years. Finally, an accuracy assessment is conducted between the test data and each land use feature. The overall classification accuracy was $97 \%$ and $98 \%$ in 1989 and 2015 respectively. Moreover, $\mathbf{9 8 \%}$ accuracy is found in erosion while $97 \%$ is found in bar deposition areas.

Keywords

GIS, Remote Sensing, Landsat, River Erosion, Change Detection, Chowhali Bangladesh

\section{Introduction}

River bank erosion is one of the frequent but the most unpredictable disasters that occur every year in Bangladesh. It is a common geomorphological phenomenon in alluvial floodplain regions. Due to its regularity of every year, river erosion is often called a "silent disaster". 
The Ganges, the Brahmaputra and the Meghna river systems comprise one of the biggest combined catchment basins of the world and create the biggest Bengal delta. Annually the river systems carry about two billion tons of sediment to Bengal Delta [1]. Numerous tributaries and connected distributaries of the major river systems are also vulnerable to the riverbank erosion process as well as flood effects. According to Islam and Islam (1985) around 2000-3000 kilometres of riverbank line face erosion annually [2]. Heavy siltation forms channel bars (Char) inside the river course and changes the direction of river flow. The mechanism creates stress on the bank of rivers and erosion occurs. In addition, heavy rainfall and sudden flooding also influence and contribute to river bank erosion.

The erosion process is very active in the Jamuna River, especially during the pre and post monsoon period and during flooding. Every year, large croplands and numerous habitation and infrastructure experience erosion. The impact of natural disasters aggravates normal livelihoods, poverty, public health, and vulnerability. Studies find that an increase of 10 percent maximum discharge of the Jamuna River generates approximately 25 percent increase in riverbank erosion [2]. The Jamuna River is a multi-channel braided river system that frequently develops sand bars and changes in river flow direction [3].

According to research, the Jamuna River embankment soil is made of poor grade sand with high siltation. The soil permeability is found moderately high with low strength properties that increases rapid submerge condition [4]. Earthen embankment does not properly protect the river bank area. In fact, it has been found that poorly earthen embankments of this river area are vulnerable to the impact of the Jamuna river water flow and heavy rainfall [1].

Geographic Information Systems (GIS) and Remote Sensing (RS) are essential tools for detecting changes along coastlines and riverbank erosion. Predictions can be made based on change detection results and trend analysis. Bedini (2007) uses Landsat imageries and GIS tools to detect changes along the coastline between the Semani and Shkumbini rivers and Central Albania and finds important changes [5]. His results detect significant erosion process at the Semani river delta, although the rate of erosion is not uniform. Gogoi (2013) conducts research on the Subansiri River in Assam, India using remote sensing and GIS technology [6]. He uses satellite imageries of 1995 and 2010 and reveals that the width of the Subansiri River has increased and that the erosion process has continued in both banks of the river.

A research work is recently carried out on riverbank erosion in Chandpur district, Bangladesh by using Landsat TM and MSS satellite imageries. According to that GIS based research, the bar deposition process is higher than the riverbank erosion process in the Meghna River in Chandpur. They also estimated that about 3517 square meter areas eroded during 1990 to 2002 [3]. Uddin (2011) conducts an assessment on morphological changes and riverbank erosion of the Jamuna River by using remote sensing [7]. In his research, he uses five different years of Landsat of $\mathrm{ETM}^{+}$, TM and MSS images and reveals very high siltation rates and erosion results. According to his result, the siltation is $29.82 \mathrm{~km}^{2}$ and average erosion alongside the Jamuna River is $1235.25 \mathrm{Km}^{2}$. Another GIS and remote sensing based investigation are conducted to examine erosion of the Jamuna River bank, where the researchers conclude that the average width of the river is increasing. The rate of increase is about 3 kilometres since last 40 years. They also calculate that average riverbank erosion is as 607 $\mathrm{km}^{2}$ and average accretion is as $166 \mathrm{~km}^{2}$ [8].

The main objectives of the study are as follows:

- To assess changes of land use patterns of the study area from 1989 to 2015.

- To estimate riverbank erosion and bar deposition areas in the study area.

\section{Study Area}

Chowhali Upazila is one of the most vulnerable regions of Bangladesh in terms of riverbank erosion. The Jamuna River along Chowhali Upazila has been suffering from riverbank erosion for long time. The research was conducted in the entire Upazila. This Upazila covers 2,1039 hectares area and located between $24^{\circ} 01^{\prime}$ and $24^{\circ} 17^{\prime} \mathrm{N}$ latitudes and between $89^{\circ} 41^{\prime} \mathrm{E}$ and $89^{\circ} 59^{\prime} \mathrm{E}$ longitudes (Figure 1). The population of the Upazila is approximately 160,063 [9]. The Upazila is bounded by Shahjadpur and Belkuchi Upazilas on the west, Tangail Sadar and Nagarpur Upazila (Tangail) on the east.

\section{Data Collection and Materials}

To conduct this research, two multi-date Landsat imageries of 1989 (TM) and 2015 (OLI_TIRS) were used. All 


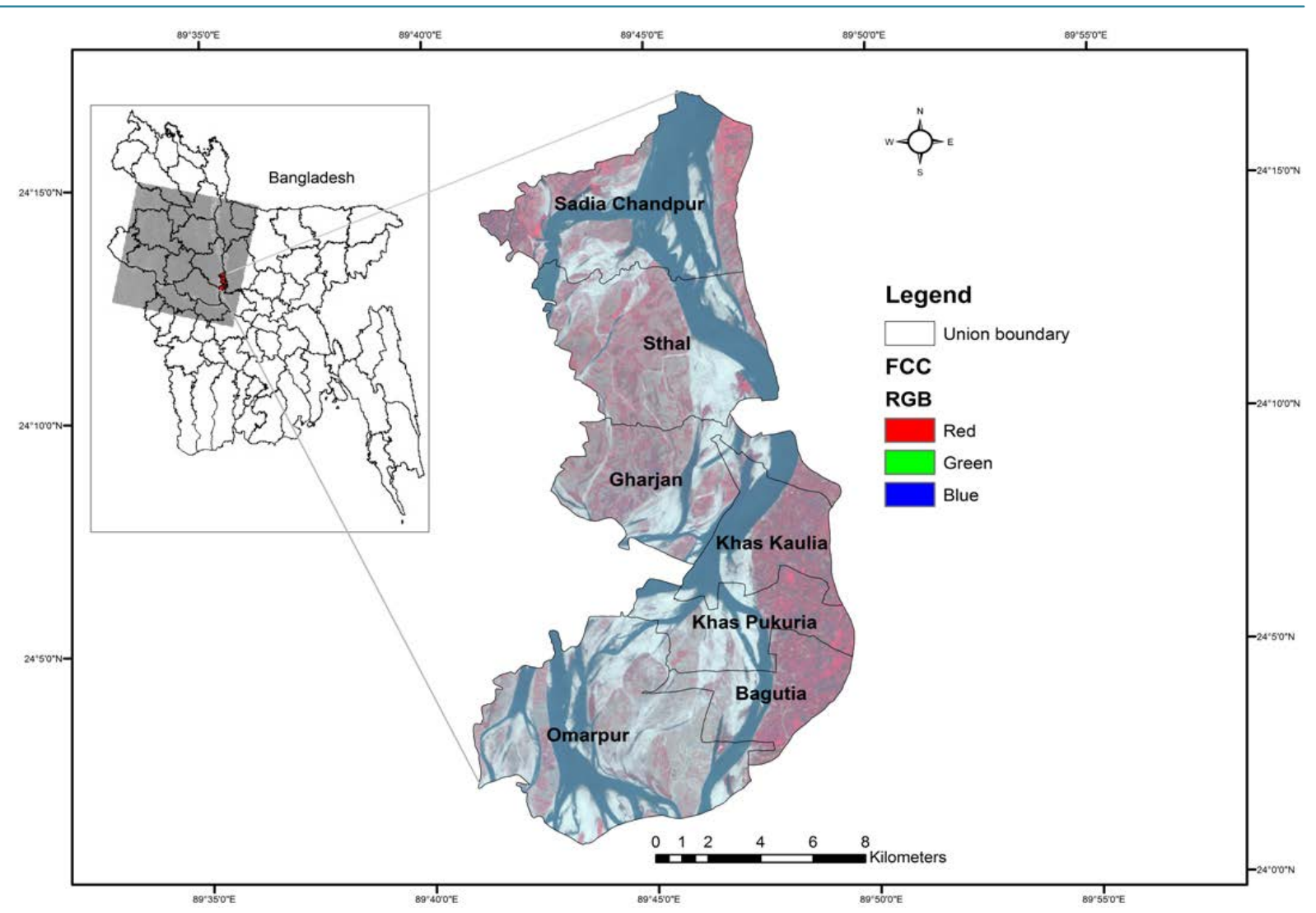

Figure 1. Location of the study area on Landsat False Colour Composite (FCC) image with union boundary shape file.

imageries used in this study were 30 meter resolution with WGS84 datum. A union shape file was collected from the Bangladesh Local Government Engineering Department (LGED) for masking the study area in order to follow digital image processing. ENVI v 4.7 and ArcGIS 10 were intensively used to complete all of the image processing tasks to generate land use, erosion and deposition maps. Moreover, Microsoft Excel was used to calculate areal information of land use, erosion and deposition of the study area. The Landsat imageries information used in the study are summarized in Table 1.

These Landsat imageries were freely downloaded from the University of Maryland's Global Land Cover Facility's Earth Science Data Interface (ESDI) website in order to classify landuse, river path, riverbank erosion and bar deposition assessment. In this study, Landsat images were used satisfactorily for the identification of area [10].

\section{Methodology}

The main methodology adopted in this study is presented in Figure 2. A 30 meter spatial resolution of Landsat imageries including blue, green, Red and NIR imageries were selected in order to classify landuse and its area statistics [11].

\subsection{Image Processing}

Digital image processing is required for satellite data classification. For mapping and extracting the whole features in this study, ENVI and ArcGIS software were used. ENVI software was used for digital image processing and analyzing, such as geometric correction, radiometric correction, atmospheric, noise removal, image clipping, classification and enhancement [10]. All sets of geocoded imageries were masked out by Upazila boundary. Supervised image classification method was used to classify land use features, erosion and deposition in the study. Post classification change detection method was also used in order to assess temporal changes of land use in the study area. 
Table 1. Two multi-date image characteristics of Landsat image characteristics.

\begin{tabular}{cccccc}
\hline Landsat & Row/Path & $\begin{array}{c}\text { Date of } \\
\text { acquisition }\end{array}$ & $\begin{array}{c}\text { Resolution } \\
\text { (Meter) }\end{array}$ & Projection & Channels \\
\hline Landsat 8-OLI_TIRS & $043 / 138$ & $2015-07-19$ & 30 & UTM/WGS 84 & Blue, Green, RED, NIR and MIR \\
TM & $044 / 138$ & $1989-07-11$ & 30 & UTM/WGS 84 & Blue, Green, RED, NIR and MIR \\
\hline
\end{tabular}

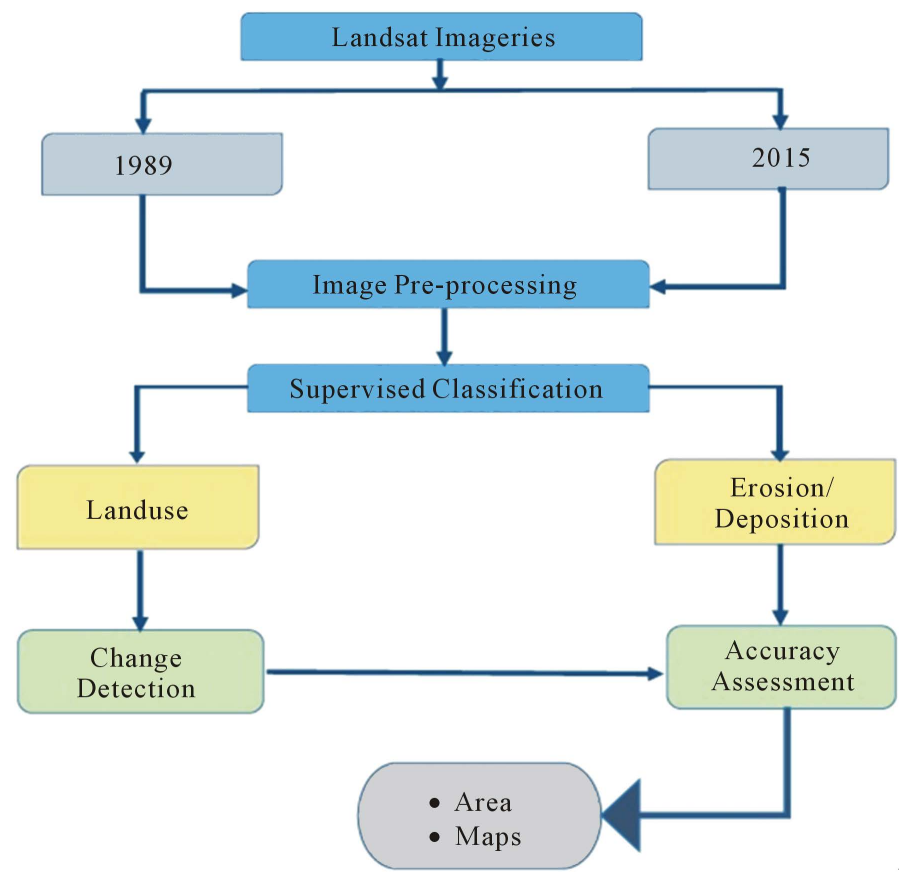

Figure 2. Methodology adopted for carrying out this study.

\subsection{Regions of Interest (ROIs)}

Regions of Interest (ROIs) are typically used to extract statistics for image classification, masking and other operations [12]. For conducting supervised image classification in this study, Regions of Interest (ROI) were required to classify remotely sensed imageries in a statistical manner. In this study, more than 4000 and 4500 pixels were selected as region of interest and classification accuracy for each feature respectively. Field investigation by GPS, local knowledge on the study area and high resolution google maps were referenced to collect region of interests in order to classify eight land features in this study. The information of each feature is summarized in Table 2.

\subsection{Supervised Image Classification}

Supervised image classification was performed to classify land use features. Supervised classification is a method in which the analyst defines small areas, called regions of interest, on the image which are representative of each desired land cover category [13]. To conduct this image classification, parametric maximum likelihood classifier was executed for all the images. This method assumes a normal distribution of DN values, allowing the function to determine the probability of a pixel belonging to a certain feature class and assign each pixel to the highest probability class [14] [15]. A set of regions of interest was extracted in order classify eight different land features, riverbank erosion and bar deposition in this study.

\subsection{Change Detection}

Change detection is an important issue for exploring changes of surface phenomena in the earth. Change detection is the process of identifying differences in the state of an object or phenomenon by observing it at different 
Table 2. Training sites and pixels with sources used in this research.

\begin{tabular}{cccc}
\hline \multirow{2}{*}{ Landuse class } & \multicolumn{2}{c}{ Pixels } & Sources \\
\cline { 2 - 3 } & ROIs & Accuracy & GPS \\
River & 4100 & 4790 & GPS \\
Forest & 4400 & 4678 & GPS \\
Agriculture & 4500 & 4876 & GPS and Google Earth \\
Seasonal crops & 4600 & 4567 & GPS \\
Sand & 4900 & 4786 & GPS and Google Earth \\
Settlement & 4300 & 4876 & GPS and community \\
Erosion & 4798 & 4656 & GPS and community \\
Deposition & 4280 & 4890 &
\end{tabular}

times [16] [17]. In this study, features extracted in 1989 were compared to 2015 classified features. To conduct this exercise, post-classification change detection statistics method was used. This method tabulates the total for each land use cover type and examines the trends between the years [17].

\subsection{Accuracy Assessment}

Each classified land feature was compared to the reference data in order to create an error matrix. An error matrix is a very effective way of representing accuracy in that the accuracies of each category are plainly described along with both the errors of inclusion (commission errors) and errors of exclusion (omission errors) present in the classification [18]. In this study, all reference data were collected from GPS and high resolution google maps. The whole error matrix, overall accuracy and kappa index were based on the Equations (1)-(3) below:

$$
\begin{aligned}
& \text { Error matrix, } n=\sum_{i=1}^{K} \sum_{j=1}^{k} n i j \\
& \text { Overall Accuracy }=\frac{\sum_{i=1}^{k} n i i}{n}
\end{aligned}
$$

where, nii is diagonal elements in error matrix; $n$ is total number of samples in error matrix

$$
\text { Kappa coefficient, } K=\frac{n \sum_{i=1}^{k} n i i-\sum_{i=1}^{k} n i+n j}{N 2-\sum_{i=1}^{k} n i+n i}
$$

where, $i$ is number of rows, columns in error matric; $N$ is total number of observations in error matrix; nij is major diagonal element for class $i$; $n i+$ is total number of observations in row $i$ (right margin); $n+j$ is total number of observations in column $i$ (bottom margin).

\section{Results and Discussions}

\subsection{Land Use Mapping}

The land use maps from 1989 and 2015 of the study area were classified based on visual interpretation, local level knowledge and digital image processing methods. United States Geological Survey (USGS) land classification level-2 was also adopted, which is in line with the existing land use categories of the study area. Six different major land use classes were classified in this study (Figure 3).

From Figure 3, forest was decreased from 1551 to 874 hectares, while the river water coverage was increased from 3453 to 6220 hectares between 1989 to 2015. Due to drastic river erosion by the Jamuna River in the study area, destruction and resettlement in settlement feature was observed. Settlements increased by more than $50 \%$ over the study period mainly due to population growth and internal migration. However, settlement patterns 


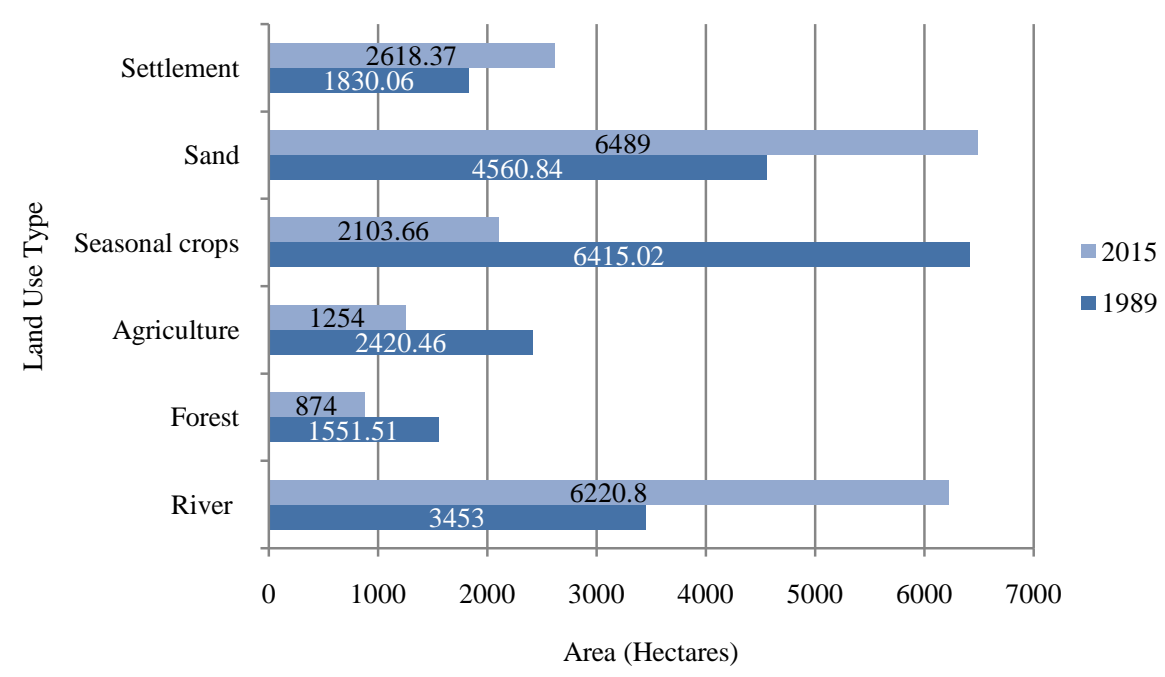

Figure 3. Post classification change detection statistics for assessing different spatial changes of the each land feature over the twenty six years.

were sporadic and non-static due to higher frequency of erosion. Seasonal crop areas have been decreased while sandy areas were expanded due to river channel migration.

\subsection{Erosion and Deposition}

Riverbank erosion and bar deposition is a common scenario in the study area. In this study, multi-date Landsat images were classified based on supervised method. The two resultant images were superimposed in order to demarcate union wise erosion and deposition areas. Local level consultation and key personnel interviews were conducted to verify classification accuracy. Figure 4 shows that most of the eroded areas were found in the Sadia Chandpur, Sthal, KashKaulia, KashPukuria and Omarpur unions.

On the other hand, higher bar deposition areas were also found in Sthal, Gharjan, Kash Pukuria, Bagutia and Omarpur unions. The total area of erosion and deposition from the all unions were estimated based on pixels calculation of change detection method. The classified information extracted from Landsat imageries is in Table 3. This table reveals that about 1340 hectare areas have been eroded while 630 hectares were deposited in the study area over the twenty six years.

Pahlowan et al. (2015) researched the relationship of erosion and accretion in terms of water discharge in the Jamuna River [19]. They found that erosion is always greater than deposition, which is in line with Table 3. Moreover, their study shows a strong relationship between water discharge and erosion. It means that if there is more discharge in the river, then the possibility of erosion is higher.

\subsection{Accuracy Assessment}

Finally, an accuracy assessment was conducted between test data and each land use feature. The overall image classification accuracy was 97\% and 98\% in 1989 and 2015 respectively. Moreover, 98\% accuracy was found in erosion while $97 \%$ accuracy was found in bar deposition areas. Poor spectral separability is found in seasonal crops and agriculture due to similar spectral profiles and location. On the other hand, a significant amount of settlements were mixed with forest spectral profiles, as most of the settlements were under forest canopy in the study area. The overall kappa statistics was 0.972 (97\%) in landuse mapping while $0.984(98 \%)$ was in erosion and deposition mapping.

\section{Conclusion}

This paper attempted to detect changes of land use, riverbank erosion and bar deposition in the study area by using multi-date Landsat imageries from 1989 and 2015. From this study, natural vegetation with forest, seasonal crops and agriculture features decrease while human settlement and river coverage are increased dramatically. 
Table 3. Erosion and deposition information extracted fromLandsat imageries.

\begin{tabular}{ccc}
\hline Year & Erosion (hectares) & Deposition (hectares) \\
\hline 1989 & 1950 & 1720 \\
2015 & 3290 & 2530 \\
Difference & -1340 & -630 \\
\hline
\end{tabular}

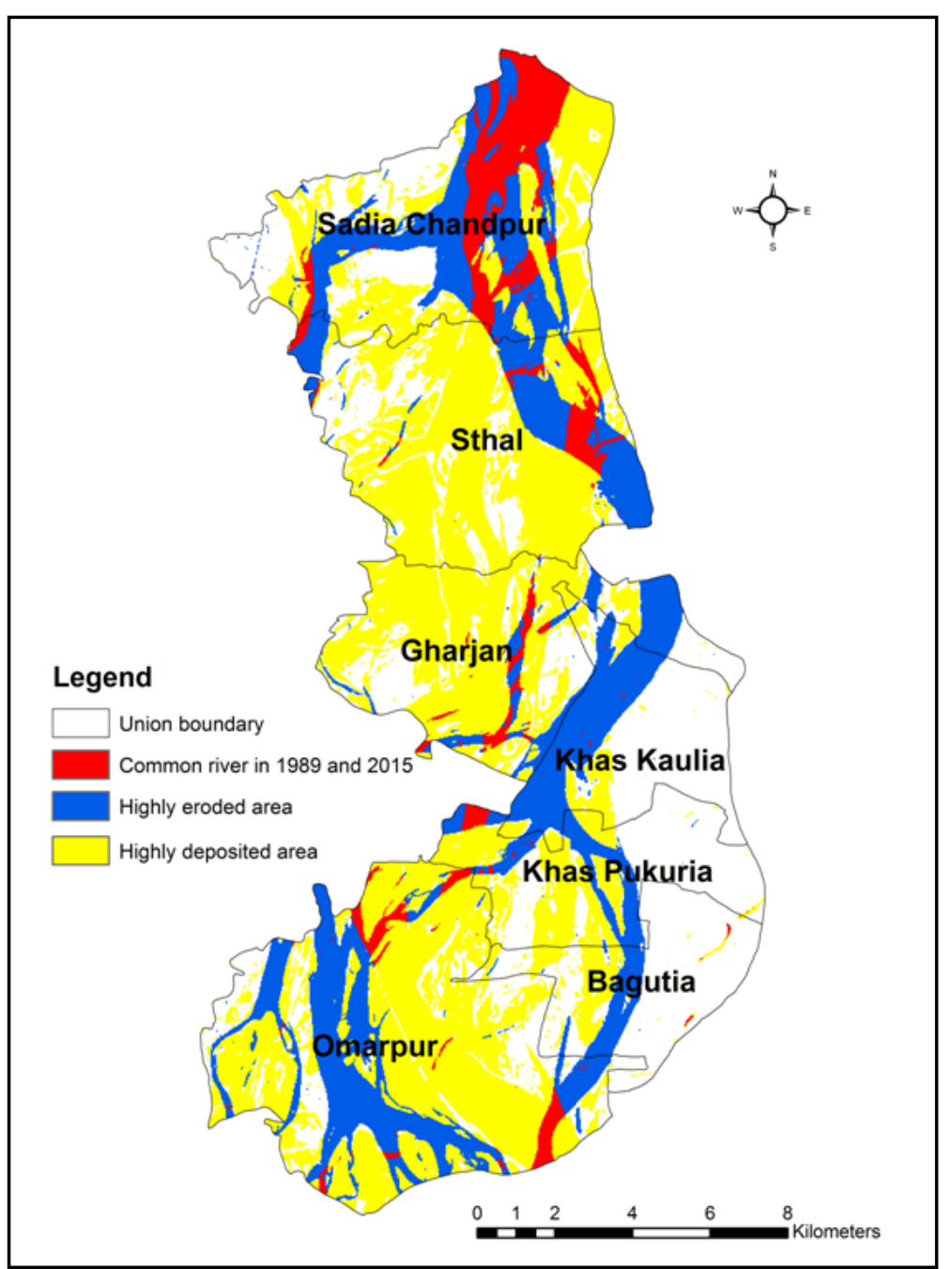

Figure 4. Union wise erosion and bar deposition areas in the study area.

About 1340 hectare areas have been eroded, whereas 630 hectares are deposited as channel bar in the study area over the last twenty-six years. To detect these changes, medium resolution (30 meters) of Landsat imageries are shown to be useful. Further research should be based on high-resolution images with field level ancillary data. Different social aspects should be included in order to enhance future planning related issues of the river management. Moreover, water discharge and rainfall data can be incorporated. Finally, this research will help to formulate any erosion and deposition related local river management as well as policy implications.

\section{References}

[1] Hossain, M.Z. and Sakai, T. (2008) Severity of Flood Embankments in Bangladesh and Its Remedial Approach. Agricultural Engineering International: The CIGR E-Journal, Manuscript LW 08 004, X, 1-11. 
[2] Islam, M. and Islam, A. (1985) A Brief Account of Bank Erosion, Model Studies and Bank Protective Works in Bangladesh. REIS Newsletter, 2, 11-13.

[3] Nath, B., Naznin, S.N. and Paul, A. (2013) Trends Analysis of River Bank Erosion at Chandpur, Bangladesh: A Remote Sensing and GIS Approach. International Journal of Geomatics and Geosciences, 3, 454-463.

[4] Hossain, B.M., Sakai, T. and Hossain, Z.M. (2010) River Embankment and Bank Failure in Bangladesh: A Study on Geotechnical Characteristics and Stability Analysis. Proceedings of International Conference on Environmental Aspects of Bangladesh (ICEAB10), Kitakyushu, September 2010, 171-174.

[5] Bedini, E. (2007) Use of GIS and Remote Sensing to Detect Change along the Coastline Segment between Shkumbini and Semani Rivers, Central Albania. Proceedings of the 11th International Congress Bulletin of the Geological Society of Greece, XXXX, Athens, 24-26 May 2007, 1916-1924

[6] Gogoi, C. and Goswami, D.C. (2013) A Study on Bank Erosion and Bank Line Migration Pattern of the Subansiri River in Assam Using Remote Sensing and GIS Technology. The International Journal of Engineering and Science (IJES), 2, 1-6.

[7] Uddin, K., Shrestha, B. and Alam, M.S. (2011) Assessment of Morphological Changes and Vulnerability of River Bank Erosion alongside the River Jamuna Using Remote Sensing. Journal of Earth Science and Engineering, 1, 29-34.

[8] Khan, I., Ahammad, M. and Sarker, S. (2014) A Study on River Bank Erosion of Jamuna River Using GIS and Remote Sensing Technology. International Journal of Engineering Development and Research, 2, 3365-3371.

[9] BBS (Bangladesh Bureau of Statistics) (2012) Community Report Sirajganj Zila June 2012. Population and Housing Census 2011, Statistics and Informatics Division, Ministry of Planning, Dhaka.

[10] Abd, H.A.A. and Alnajjar, H.A. (2013) Maximum Likelihood for Land-Use/Land-Cover Mapping and Change Detection Using Landsat Satellite Images: A Case Study "South Of Johor”. International Journal of Computational Engineering Research, 3, 26-33.

[11] Hassan, M.S. and Mahmud-ul-Islam, S. (2014) Identification of Wetland Restoration Areas of Chalan Beel inSirajganj District, Bangladesh Using Integrated GIS and Remote Sensing. New York Science Journal, 7, 94-100.

[12] ENVI (2015) How to Create ROIs in ENVI 5. EXELIS: Visual Information Solutions. http://www.exelisvis.com/Support/HelpArticles/TabId/185/ArtMID/800/ArticleID/5244/5244.aspx

[13] Rani, M., Kumar, P., Yadav, M. and Hooda, R.S. (2011) Wetland Assessment and Monitoring Using Image Processing Techniques: A Case Study of Ranchi, India. Journal of Geographic Information System, 3, 345-350. http://dx.doi.org/10.4236/jgis.2011.34032

[14] Lillesand, T.M., Kieffer, W.R. and Chipman, J.W. (2004) Remote Sensing and Image Interpretation. 5th Edition, John Wiley \& Sons Inc., New York, 763.

[15] Lee, S. (2011) Detecting Wetland Change through Supervised Classification of Landsat Satellite Imagery within the Tunkwa Watershed of British Columbia, Canada. Bachelor Degree Project in Geomatics, Hogskolan I Gavle, Gävle.

[16] Singh, A. (1989) Digital Change Detection Techniques Using Remotely-Sensed Data. International Journal of Remote Sensing, 10, 989-1000. http://dx.doi.org/10.1080/01431168908903939

[17] Nori, W., Elsiddig, E.N. and Niemeyer, I. (2008) Detection of Land Cover Changes Using Multi-Temporal Satellite Imagery. The International Archives of the Photogrammetry, Remote Sensing and Spatial Information Sciences, 37, 947-952.

[18] Congalton, R.G. (1991) A Review of Assessing the Accuracy of Classifications of Remotely Sensed Data. Remote Sensing of Environment, 37, 35-46. http://dx.doi.org/10.1016/0034-4257(91)90048-B

[19] Pahlowan, E.U. and Hossain, A.T.M.S. (2015) Jamuna River Erosional Hazards, Accretion \& Annual Water DischargeA Remote Sensing \& GIS Approach. Proceedings of the 36th International Symposium on Remote Sensing of Environment, Berlin, 11-15 May 2015, 831-835. http://dx.doi.org/10.5194/isprsarchives-xl-7-w3-831-2015 